\title{
Gait Analysis of Foot Drop in the Anatomic Plan Using the Walkaide ${ }^{\circledR}$ Device
}

\author{
FMFBM Aragão ${ }^{1 *}$, AVM Inocêncio ${ }^{1}$, EM Aragão Junior ${ }^{1}$, JC Vieira ${ }^{1}$, C Rodrigues ${ }^{2}$, CS Silveira ${ }^{1}$, MAB Rodrigues ${ }^{1}$ \\ ${ }^{1}$ Federal University of Pernambuco (UFPE), Recife, Brazil \\ ${ }^{2}$ University of Porto, Porto, Portugal Flavia, Portugal \\ *Corresponding Author: FMFBM Aragão, Federal University of Pernambuco (UFPE), Recife, Brazil.
}

Received: September 26, 2019; Published: October 11, 2019

DOI: 10.31080/ASMS.2019.03.0436

\begin{abstract}
The human gait shows the single efficiency and functionality and can be considered the most complex functional activity of the human being. Foot drop can be defined as a significant weakness in the dorsal flexion of the foot. The functional electrical orthosis (FEO) are devices that use electrical stimulation to promote functional movements. Besides the FEO promotes the improvement of muscular tropism, this mechanism can be a source of relearning, because all events are interpreted by the body as his owns. This research sought to analyze the impact of the electrostimulation through the Walkaide ${ }^{\circledR}$ system in the angular movement of individuals with foot drop. The data were collected from seven pa- tients and the focus of the evaluation of this research was the subtalar joint angle. After analyze the results, it could be seen that the Walkaide ${ }^{\circledR}$ promoted a signif- icant gait improvement, meanly about the compensatory movements.

Keywords: Rehabilitation Drop Foot; Functional Electrical Stimulation
\end{abstract}

\section{Introduction}

One of the determining characteristic of the human being is the ability of walk erect, in a rhythmic way and, theoretically, without effort or with minimum energy expenditure. The act of walk is a continuous event that consists in transfer the weight of one lower limb to the other, with the goal of advance the body forward at the same time that suc- cessful imbalances happens [1].

The reduced ability to walk is one of the functional problems frequently related in patients with lower palsy. Some of the source of complains presented by them are cor- related with the changes of voluntary control of the limb, integrity of proprioception and of the movement [2].

Foot drop is not characterized as a disease, but a temporary or perpetual sequel due a stroke, cerebral palsy, incomplete spinal injury, neuropathy, diabetes or any type of cerebral trauma. In these cases, the patient presents the incapacity of stand up the frontal part of the foot, dragging their fingers on the floor. Trying to walk in this condition, the patients end up elevating more the knee and the hip, interfering the achievement of a correct gait.

The functional electrical stimulation (FES) can be defined as a controlled nerve ac- tivation, using a lower frequency current to promote a contraction in some inactive muscles. This technic can be an alternative to rehabilitation in patients with foot drop, be- cause the stimulus of the peripheral nervous system can restore the elevation of the frontal part of the foot $[3,4]$.

This paper sought to analyze the use of electrostimulation through the Walkaide ${ }^{\circledR}$ system in the angular movement of the ankle in the swing phase of the gait on individ- uals with foot drop. This research aims the future development of electrostimulation equipment with Brazilian technology and low cost.

\section{Background}

Human gait

The gait is a succession of alternate and rhythmic movements of the limbs and the body, raising an anterior displacement of the body gravity center [5]. Each individual presents a peculiar gait pattern to move in the environment with the minimum possible effort, besides the habitual and selective control to presents proper stability and acceptable appearance [1]. The act of many muscles is involved in the gait, and many combinations of different muscle forces can result in the same model f movement [5].

The human gait is carefully distributed in a cycle and subdivided in phases. The gait cycle phases compose the activities that occurs since the initial touch point of the foot in the floor to the point that the same foot touches the floor again [6].

Each extremity goes through two phases during the cycle, a phase of support and a phase of oscillation. The stance phase be- 
gins with the movement that one extremity goes in contact with the floor and continues while the foot keeps in contact. This phase corresponds to $60 \%$ of the gait cycle. The swing phase begins when the foot drops out the floor and end right before his contact with the soil. The phase corresponds about $40 \%$ of the gait cycle (walking rhythm) [7].

\section{Foot drop}

The pathology gravity determines the difficulty degree to execute the movement and usually the patient uses the remains functions to complete the movement. The result gait pattern is a combination of deviations caused by the primary dysfunction and by the movement established by the remain function [8].

The drop foot is defined by a significant weakness in the dorsal flexion of the foot. The more affected muscles are the anterior tibial, longus extender of the hallux and the longus extender of the fingers, because they realize the dorsiflexion of the foot during gait [3].

The patient that presents hemiparetic gait has angular restrictions in the ankle, knee and hip because of the tonus increase of the extensor musculature of the lower limbs. The gait becomes misaligned, because requires the realization of the lateral movement of the lower limb during the oscillation phase, characterizing an abnormal gait. Thus, the gait restoration acts essentially in rehabilitation, turning the movement more inde- pendent and facilitating his cares [9].

Functional electrical orthesis: functional electrostimulation and Walkaide

The Functional Electrical Stimulation (FES) is used in a tentative of reconstruct the neuro muscle function lost or injured, through the application of electrical pulses. The FES is a category of electrotherapy used in muscles with lesion in the motor superior neuron, always with the goal of realize functional movements. This technique is largely applied in patients with foot drop, because it can improve the force, reduce the spastic- ity, correct the gait and its velocity. The FES uses an electrical current applied by elec- trodes on the skin surface to produce depolarization of the motor nerve, resulting in a muscle contraction capable to product functional movements [10].

The functional electrical orthesis (FEO) is a device that uses functional electrical stimulation to promote functional movement. The current profiles used in these devices causes a stimulus that arrives in the central nervous system and product active movement in the patient. Besides promote improvement in the muscle tropism, this mecha- nism serves also as a relearning, because all events are understood as their own [11].
The Walkaide ${ }^{\circledR}$ is a non-invasive and autonomous device projected specific to pro- vide transcutaneous electrical stimulation comfortable to the patient. The stimulation affects directly the common fibular nerve and the anterior tibial muscle, with the goal of improve the dorsiflexion during the swing phase of the gait. The Walkaide ${ }^{\circledR}$ system fits inside of a support surrounded in the patient leg, below the knee. The device in- cludes slope sensors, with accelerometers and inclinometers to measure the position and velocity of the leg to provide the stimulation in the correct moment [12].

The generated impulses are delivered to the transcutaneous self-adhesive electrodes positioned on the fibular common nerve and in the tibial anterior muscle belly. The stimuli are offered through electric current pulses with low intensity, with duration and amplitude enough to produce action potentials in peripheral nerves. The slope sensors activate the dorsiflexion in all swing phase, reducing or eliminating completely the drop of the foot and turning the gait normal [12].
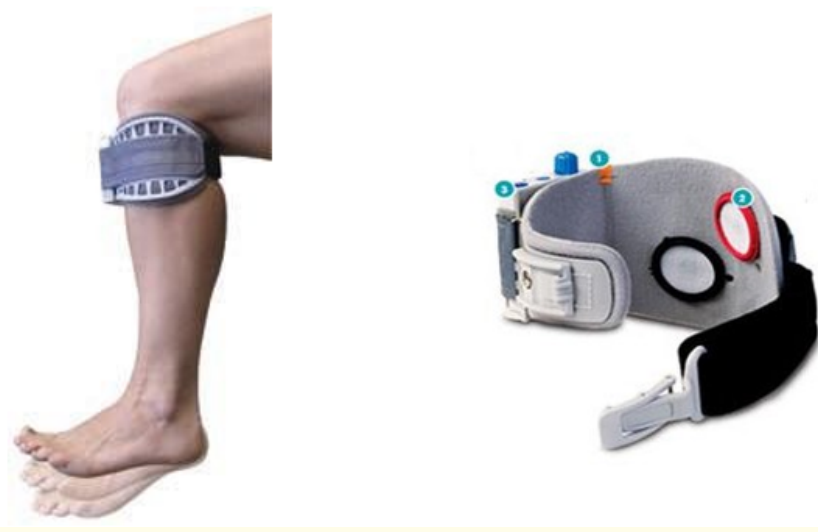

Figure 1: The Walkaide ${ }^{\circledR}$ system. Adopted from Clinician Manual [13].

The Walkainde system parameters are adjusted using software walkAnalist provided by the manufacturer website. The system communicates with the software through the Bluetooth communication protocol when the system is connected with another device called Walklink.

\section{Materials and Methods}

This research consists in a pilot study. It is a qualitative and quantitative cross-sectional study and was realized after the approval of the research ethics committee of UFPE with the CAAE protocol 55850616.1.0000.5208.

In this study were included adult people with age between 18 and 75 years old in both genders that presented unilateral foot drop, prevenient of a central nerve lesion, independent of the etiology but not carrier of a dysfunction in the neuromuscular pe- riph- 
eral complex. Also, the volunteers also had no important limitation of the active or passive movement amplitude of the ankle joint to the dorsiflexion and of the knee joint to the flexion. The sample was composed of seven (7) volunteers. Two volunteers were female $(28.6 \%)$ and five were male $(71.4 \%)$.

In this research, the participants were excluded if they needed a support exclusive to walk, like a crutch, a walking stick or an orthosis. Another criterion was if the patient had cognitive problems that turned incapable to understand the directions for the data acquisition. The patients with level greater than 2 in the modified Ashworth scale were also excluded.

The data acquisition was obtained in the Laboratory Kinesiology and Functional Evaluation (LACAF), in the Department of Physioterapy of the UFPE, between May/2017 and June/2017. The patient visited the laboratory just one time and the pro- cedure were divided in three steps:

- After a clinical evaluation, a static acquisition was acquired with the Qualisys Pró-Reflex system. In this step, the volunteer stayed in an orthostatic position with the two feet on the floor and the crossed arms for a period of 5 seconds in the system begin. The sample rate of the system acquisition was set in $81 \mathrm{~Hz}$ in the Qualisys software.

- A dynamic acquisition in which the volunteer walked a 5 meters' distance in a medium period of 10 seconds three times.

- In this step, the Walkaide system was settled based in the clinical manual. The volunteer walked also three times the same trajectory of the $2^{\text {nd }}$ step using the Walkaide system adapted to him.

For the data acquisition, it was used the Qualisys Pro-reflex system, figure 2 . This sys- tem is considered a golden pattern by several authors like Kirkwood., et al. [14] that had the goal in his study to develop and test the reliability and validity of the GaitGrabber system in obtaining kinematic data from the sagittal plan during the gait. Araújo., et al. [15] conducted a similar study to develop a observational gait scale and characterize paralyzed brain children using this same system.

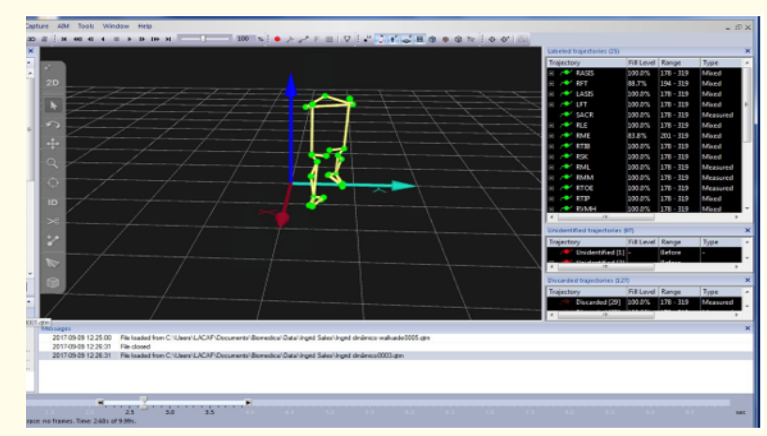

Figure 2: Qualisys system interface with the capture model in the frontal plan. Source: personal archive.
The Qualisys system used is composed of 6 infrared cameras disposed in a room with $40 \mathrm{~m}^{2}$. Those cameras catch the position of passive reflexive markers that are po- sitioned in specific places. In the beginning of the capture, the system was calibrated as recommended by the manufacturer's manual.

The Visual 3D software was used to create a biomechanical model and process the kinematic data. To identify correctly the parts of the body, markers were mainly placed on: Ilium Anterior Superior, Sacrum, Femur greater Trochanter, Femur Lateral Epicon- dyle, Femur Medial Epicondyle, Head of Tibia, Fibula Apex of Lateral Malleolus, Tibia Apex of Medial Malleolus, Posterior Surface of Calcaneus, Head of 5th Metatarsus and Head of 2nd Metatarsus. The choice of marker's places was based in in the segment definitions in C-Motion tutorial [16].

After the acquisition, the markers were labelled and the file was exported to the Vis- ual 3D software, to do the analysis of the movement. A pipeline was created to calculate the ankle angle during gait in the frontal plan, as see in figure 3 . The angle variation in $\mathrm{X}$ - axis represents the flexion/extension, in Y-axis represents the abduction/adduction and in Z-axis represents the longitudinal rotation. The neuter angle for dorsiflexion is $90^{\circ}$ according the American Academy of Orthopaedic Surgeons.

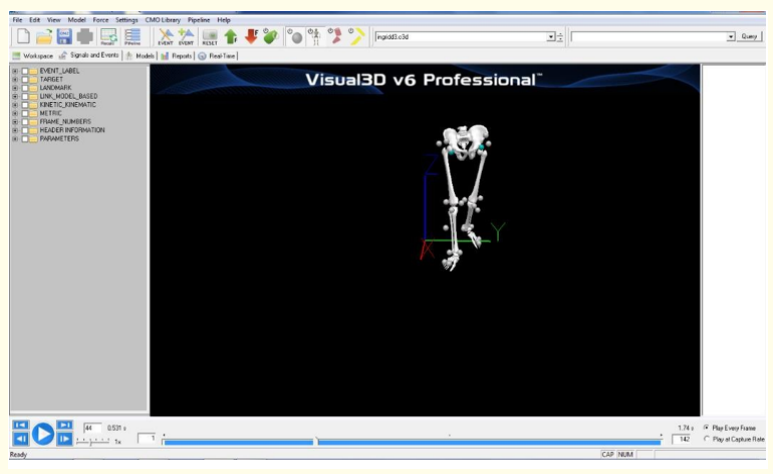

Figure 3: Biomechanical model vision in Visual $3 \mathrm{D}$ in the frontal plan.

The statistical analysis was made in the Biostat 5.3 software, in which the Kolmo- gorov-Smirnov normality test was applied. The null hypothesis tested was there was normal distribution between the categories and this hypothesis was rejected.

\section{Results and Discussion}

The data processed by the Visual 3D software for the subtalar ankle's joint in the Y- axis from the Cartesian plan and the anatomic frontal plan. The executed movement shows the lateral and medial deviation of the foot. The table 1 describes the ankle angle for each patient. 


\begin{tabular}{|l|c|c|c|}
\hline \multirow{2}{*}{ Patients } & \multicolumn{3}{|c|}{$\begin{array}{c}\text { Variation of the foot arch movement in } \\
\text { the frontal plan during gait(o) }\end{array}$} \\
\hline & With Walkaide $^{\circledR}$ & Without Walkaide $^{\circledR}$ & p-value \\
\hline 1 & $0.70 \pm 2.11$ & $1.65 \pm 1.84$ & $0.000^{*}$ \\
\hline 2 & $-6.06 \pm 8.64$ & $-9.36 \pm 7.40$ & $0.001^{*}$ \\
\hline 3 & $-5.76 \pm 5.64$ & $-6.97 \pm 5.10$ & $0.094^{*}$ \\
\hline 4 & $20.23 \pm 3.75$ & $19.95 \pm 2.63$ & $0.003^{*}$ \\
\hline 5 & $-0.02 \pm 6.47$ & $3.32 \pm 5.99$ & $0.000^{*}$ \\
\hline 6 & $-2.73 \pm 4.77$ & $-9.34 \pm 6.24$ & $0.000^{*}$ \\
\hline 7 & $-2.98 \pm 2.40$ & $-3.82 \pm 2.48$ & $0.000^{*}$ \\
\hline
\end{tabular}

Table 1: Patient's results.

*Wilcoxon test, with significant level to $\mathrm{p}<0.05$.

After the realization of the Komogorov Smirnov normality test in all samples, it was noticed that the graph curve was not normal. For that reason, the analysis was made with the non-parametric test of Wilcoxon for the dependent data from each patient and with the Mann Whitney's test to the independent samples to do a comparation between all patients in the subtalar joint angle of Y-axis in the frontal plan. All tests were run with the null hypothesis that there is no difference between the groups, with $p$ - value $<0.05$.

According to table 1, the acquired data, obtained from the variation of the foot arch movement in the frontal plan during gait had a significant difference in 6 of 7 volunteers ( $85.7 \%$ of the patients). Various researches report that the use of this angle reveals the foot alignment with the tibia bone during gait $[5,17,18]$. This angle should be about zero when the person is stopped and his variation represents a gait pattern. Otherwise, when the averages of each patient are compared, there is no significant statistical vari- ation, as described in Table 2. This result represents the impact of the use of the device in the volunteer's gait pattern when observed separately.

\begin{tabular}{|c|l|c|}
\hline \multicolumn{3}{|c|}{$\begin{array}{c}\text { Variation of the foot arch movement in the } \\
\text { frontal plan duringgait( }(\stackrel{)}{)})\end{array}$} \\
\hline With Walkaide ${ }^{\circledR}$ & Without Wal- kaide $^{\circledR}$ & p-value \\
\hline $0.08 \pm 2.11$ & $-0.31 \pm 1.84$ & $0.952^{*}$ \\
\hline
\end{tabular}

Table 2: Average ( \pm standard deviation) and p-value of the angle variation in frontal plans for all patients.

*Mann Whitnet test, with significant level to $\mathrm{p}<0,05$.

Comparing the angle variation between the movement range of the foot in the frontal plan, it can be noticed, in absolute numbers, that the average with the Walkaide system represents an adduction movement, leaving the foot closer to the medial line. With this improvement, there is a reduce of the foot deviations during the gait. Statistically, there were no significant difference. These results can be a reflex of the absence of the train- ing and adaptation phase of the equipment.
After an analysis, it was observed that the patients use compensations to adjust the deviation caused by the primary dysfunction to adept gait with foot drop. In this context, important findings could be observed like the improvement of the compensatory move- ments of the ankle, where was observed a positive variation of the angle in the frontal plan in 5 of 7 volunteers (Table 1).

With the improvement of adduction because of the device, there were the reduction of abrupt movements in the swing phase of the patients. These movements are realized to avoid the foot to touch the floor. Otherwise, when compared the angle variation of all patients there was no statistical significance $(\mathrm{p}=0.952)$, with average without the de- vice being $0.08 \pm 2.11$, and the average with the device $-0.31 \pm 1.84$.

In figure 4 , it is possible evaluate the blue variable that corresponds to the gait without the Walkaide system. There is a positive variation from the subtalar joint angle, more evident between 11.5 seconds and 2.5- 3 seconds. This variation implies in a lateral detour during gait. This result reflects the gait from the foot drop patients and can cor- responds to an instable gait with drop risks. The behavior of the subtalar joint angle in the frontal plan (Y-axis) contains a greater variation when compared with the red trace, the gait with the Wakaide system. Even with a negative variation in the beginning, probably because of the adaptation, it is possible to notice that after 0.5 seconds, the gait is more regular, showing a stability in the gait pattern with the device.

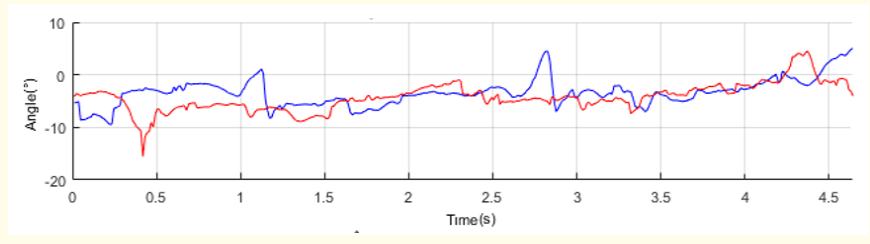

Figure 4: Comparation between the subtalar joint's angle of the patient in the frontal plan Y-axis with Walkaide(red) and without Walkaide(blue).

\section{Conclusions}

During the Qualisys capture and visual 3D analysis, it was possible to notice that pa- tients with foot drop use compensatory movements to adjust the deviations caused by the primary dysfunction. In this context, it was possible to improve the compensatory movements from the lateral and medial deviations from the foot during $85.6 \%$ of the captured sample, corroborating with the research of Sheffler and Chae [19] and Nolan., et al. [20].

These findings can be identified because of the stimulation form, promoting a gait close to the normal pattern and helping the patient to reduce the compensatory move- ments and to maintain 
the subtalar joint angle without abnormal variations. This con- dition produces a foot alignment and promotes a stable gait with voluntary motor control.

After analyze the results, it was possible conclude that the Walkaide ${ }^{\circledR}$ device pro- moted a significant gait improvement related to the physiological movements and also to the compensatory movements. This was found when the results were analyzed individually, but in the comparison of all patients, there were no significant variation. This research raises thoughts on some advances in the use of this portable electrical stimu- lation technique to correct some difficulties encountered in the data collection with the use of Walkaide ${ }^{\circledR}$ device. This technique corrects the gait of patients with foot drop to become closer to normal gait.

\section{Bibliography}

1. RIBAS DIR., et al. "Estudo comparativo dos parâmetros angulares da marcha humana em ambiente aquático e terrestre em indivíduos hígidos adultos jovens". Revista Brasileira de Medicina do Esporte 13.6 (2007): 371-375.

2. OVANDO AC. "Acidente vascular encefálico: comprometimento motor dos membros in- feriores e alterações na marcha". Revista Digital - Buenos Aires - ANO 14.132 (2009).

3. RESENDE GP. de. Equipamento de Biofeedback para Tratamento Fisioterápico em Paci- entes Portadores de Pé Equino. Dissertação de Mestrado - Programa de Pós-Graduação em Engenharia Biomédica, Universidade Tecnológica Federal do Paraná, Curitiba (2014).

4. CALHAU Ana., et al. "Análise cinemática da marcha. Disciplina de biomecânica do movi- mento. Mestrado integrado em engenharia Biomédica. Instituto Superior Técnico- Departamento de Física, 4o Ano, 1o Semestre 2007/08.

5. ROSE J and GAMBLE JG. Marcha Humana. 2 ed. São Paulo: Premier (1998).

6. SOUSA ASP. de. Análise da Marcha Baseada em Correlação Multifactorial. Dissertação de Mestrado- Mestrado em Engenharia Biomédica, Faculdade de Engenharia da Universidade do Porto (2013).

7. BRANDALIZE D and BRANDALIZE M. "Efeitos da toxina botulínica no tratamento do pé equíno em indivíduos com sequelas de acidente vascular encefálico'. Voos Revista Polidisciplinar Eletrônica da Faculdade Guairacá 2.2 (2011).

8. ZUGE RW and MANFFRA EF. "Efeitos de uma intervenção cinesioterapêutica e eletrote- rapêutica na cinemática da marcha de indivíduos hemiparéticos". Fisioter movimento 22.4 (2009): 547-556.

9. AGNE JE. "Eletrotermoterapia: teoria e prática”. Santa Maria: Orium (2005).
10. ROBBINS SM., et al. "The therapeutic effect of functional and transcutaneous electric stimulation on improving gait speed in stroke patients: a meta-analysis". Archives of physical medicine and rehabilitation 87.6 (2006): 853-859.

11. GONÇALVES BA., et al. Órteses: orientações e cuidados. XIV Encontro Latino Americano de Iniciação Científica e X Encontro Latino Americano de Pós-Gra- duaçãoUniversidade do Vale do Paraíba (2011).

12. CAMERON MH. "The walkaide ${ }^{\circledR}$ functional electrical stimulation system - A novel ther- apeutic approach for foot drop in central nervous system disorders". US Neurology 6.2 (2010): 112-114.

13. Walkaide Homepage.

14. KIRKWOOD RN., et al. "Sistema Gait Grabber na captação de dados cinemáticos durante a marcha". Motriz. Revista de Educação Física 18.3 (2012): 505-514.

15. ARAÚJO PA., et al. "Validity and intra- and inter- rater reliability of the Observational Gait Scale for children with spastic cerebral palsy". Revista Brasileira de Fisioterapia, São Carlos 13.3 (2009): 267-273.

16. C-motion Homepage.

17. CALAIS - GERMAIN B. "Anatomia para o movimento: introdução à análise das técnicas corporais". 1 (1991).

18. HALL SJ. Biomecânica Básica. 4⿳亠丷a edição, Rio de Janeiro: Guanabara Koogan (2005).

19. SHEFFLER LR and CHAE J. "Technological advances in interventions to enhance post- stroke gait". Physical Medicine and Rehabilitation Clinics of North America 24.2 (2013): 305.

20. NOLAN KJ., et al. "Changes in center of pressure displacement with the use of a foot drop stimulator in individuals with stroke". Clinical Biomechanics 30.7 (2015): 755-761.

Volume 3 Issue 11 November 2019 (C) All rights are reserved by FMFBM Aragão., et al. 